Note

\title{
Improvement in the High-Fat Diet-Induced Dyslipidemia and Adiponectin Levels by Fish Oil Feeding Combined with Food Restriction in Obese KKAy Mice
}

\author{
Masaki Wakutsu, Nobuyo Tsunoda ${ }^{\dagger}$ Yasuki Mochi, Mitsuki Numajiri, \\ Sachiko Shiba, Etsuko Muraki, and Keizo Kasono \\ Department of Clinical Dietetics and Human Nutrition, Faculty of Pharmaceutical Sciences, Josai University, \\ 1-1 Keyakidai, Sakado, Saitama 350-0295, Japan
}

Received October 4, 2011; Accepted January 18, 2012; Online Publication, May 7, 2012

[doi:10.1271/bbb.110743]

The effect on weight reduction of fish oil combined with food restriction in comparison with that of beef tallow was investigated in high-fat diet-induced obese KKAy mice. Although the reduction of body and white adipose tissue weight was similar in the two groups, fish oil increased adiponectin levels in the plasma, improved dyslipidemia accompanied by suppression of lipid synthesis in the liver when compared with beef tallow.

Key words: fish oil; food restriction; weight reduction; dyslipidemia; adiponectin

Obesity is one of the major health problems in the world. It is causally linked to metabolic syndrome, which is characterized by insulin resistance, dyslipidemia, and hypertension. ${ }^{1-4)}$ Weight reduction is necessary for obese persons to improve these metabolic disorders. Weight loss of only $5-10 \%$ has been shown to reduce or eliminate metabolic disorders induced by obesity, ${ }^{5,6}$ while ingesting a fish oil diet ad libitum has had a preventive effect on obesity and metabolic disorders caused by a high-fat diet. ${ }^{7-9)}$ Several studies have reported that fish oil or $n-3$ fatty acids combined with energy restriction was more effective in improving blood parameters when compared with only energy restriction. ${ }^{10-14)}$ However, there is continuing debate about whether fish oil and n-3 fatty acids contribute to weight reduction. Adding to this debate, several reports have suggested that the supposed effects of fish consumption on blood parameters were diminished when adjusting for weight reduction, and these effects were thus attributed to weight reduction. ${ }^{10,13)}$ In addition, direct comparisons between fish oil and other oils containing a lot of saturated fatty acids, such as beef tallow or lard in combination with a restricted diet remain to be elucidated. In this study, we investigated that the effect of fish oil combined with food restriction on weight reduction in comparison with that of beef tallow with a restricted diet in high-fat diet-induced obese KKAy mice.

KKAy mice were obtained from CLEA Japan, Inc. (Tokyo, Japan) at $5 \mathrm{wk}$ of age. They had free access to a standard MF pelleted diet (Oriental Yeast, Tokyo, Japan) and water for $1 \mathrm{wk}$ to accommodate them to the new environment before the experiments began. The mice were maintained at a constant temperature of $23 \pm 3{ }^{\circ} \mathrm{C}$ and humidity of $55 \pm 10 \%$ with a 12-h light/ dark cycle. All procedures were approved by the Animal Care and Use Committee of Josai University.

Each experimental diet consisted of $30 \%$ fat on a calorie basis. The composition of each diet was based on AIN-93G ${ }^{15)}$ with the modifications previously described. ${ }^{16)}$ Beef tallow or fish oil was used in the diet instead of soybean oil (the B diet and F diet, respectively), and the commercial MF diet was used as the control diet. Casein, sucrose, $\beta$-starch, vitamin mixture, mineral mixture, cellulose powder and beef tallow were purchased from Oriental Yeast (Tokyo, Japan). LCystine, and $t$-butylhydroquinone were purchased from Wako Pure Chemical Industries, Ltd. (Osaka, Japan), and fish oil was presented by NOF Corporation (Tokyo, Japan). The diets were made following the procedure previously described. ${ }^{16)}$ The fatty acid compositions of the dietary oils are shown in Table 1. Fatty acids in soybean oil and fish oil were measured by gas chromatography, and those in beef tallow were based on the food composition table of Japan. Soybean oil was used in the MF diet.

The mice were given free access to water throughout the study. They were fed the B diet ad libitum for $3 \mathrm{wk}$ to induce obesity and then assigned to three groups $(\mathrm{n}=4)$, after which they were fed either the B diet ad libitum (BA), the $\mathrm{B}$ diet under restriction (BR), or the $\mathrm{F}$ diet under restriction (FR) for $3 \mathrm{wk}$. As a control, mice were fed the MF diet ad libitum for all periods (Control). Mild weight reduction was induced during the food restriction period. Mice were initially fed $80 \%$ of the food intake they had experienced during the obesity induction period (Control: $15.4 \pm 1.5 \mathrm{kcal} / \mathrm{d}$; BA: $21.9 \pm 1.0 \mathrm{kcal} / \mathrm{d}, p<0.01)$. The food intake was then decreased $10 \%$ for about a week to $60 \%$ with the aim of obtaining a similar final body weight to that of the control group $(60 \%$; BR: $12.5 \pm 0.2 \mathrm{kcal} / \mathrm{d}, \mathrm{BF}: 12.6 \pm$ $1.3 \mathrm{kcal} / \mathrm{d})$. The body weight of mice was measured once weekly or more during the experimental period. Respiratory quotient (RQ) was measured after consuming the diet for $5 \mathrm{wk}$. An MK-5000RQ acrylic metabolic chamber and gas analyzer (an $\mathrm{O}_{2} / \mathrm{CO}_{2}$ metabolism measuring system for small animals; Muromachi Kikai Co., Ltd., Tokyo, Japan) were used to measure RQ. Mice

To whom correspondence should be addressed. Fax: +81-49-271-7229; E-mail: ntsunoda@josai.ac.jp 
Table 1. Composition of Fatty Acids of Dietary Oils

\begin{tabular}{llccc}
\hline $\begin{array}{c}\text { Fatty acid } \\
(\%)\end{array}$ & & $\begin{array}{c}\text { Soybean } \\
\text { oil }\end{array}$ & $\begin{array}{c}\text { Beef } \\
\text { tallow }\end{array}$ & $\begin{array}{c}\text { Fish } \\
\text { oil }\end{array}$ \\
\hline $14: 0$ & (Myristic acid) & 0.1 & 2.5 & 3.0 \\
$16: 0$ & (Palmitic acid) & 9.7 & 26.1 & 18.2 \\
$16: 1$ & (Palmitoleic acid) & - & 3.0 & 4.2 \\
$18: 0$ & (Stearic acid) & 3.7 & 15.7 & 4.9 \\
$18: 1 \mathrm{n}-9$ & (Oleic acid) & 26 & 45.5 & 18.8 \\
$18: 2 \mathrm{n}-6$ & (Linoleic acid) & 50 & 3.7 & 1.3 \\
$18: 3 \mathrm{n}-3$ & ( $\alpha$-Linoleic acid) & 7.1 & - & 0.8 \\
$20: 0$ & (Arachidic acid) & 0.4 & - & - \\
$20: 4 \mathrm{n}-6$ & (Arachidnic acid) & 0.1 & - & 2.0 \\
$20: 5 \mathrm{n}-3$ & (EPA) & - & - & 6.8 \\
$22: 0$ & (Behenic acid) & 0.5 & - & - \\
$22: 5 \mathrm{n}-6$ & (Docosapentaenoic & - & - & - \\
& acid; DPA) & & & \\
$22: 6 \mathrm{n}-3$ & (DHA) & - & - & 22.8 \\
& & $15: 26: 57$ & $41: 45: 4$ & $10: 10: 14$ \\
S:M:P & & 7.0 & 20.2 & 0.1 \\
n-6/n-3 & & & & \\
ratio & & & & \\
\hline
\end{tabular}

Fatty acids in soybean oil and fish oil were measured by gaschromatography, and those in lard were based on the food composition table of Japan. Soybean oil was used in the MF diet.

in the groups were placed in the metabolic chamber, room air was pumped through the chambers, and expired air was directed to the gas analyzer. The data was collected every $3 \mathrm{~min}$ for more than $24-\mathrm{h}$. RQ was calculated as the mean value of the 12-h light (7:00 19:00) and the 12-h dark (19:00-7:00) measurements. Mice had free access to water and the same amount of diet as in their home cages during the period in the metabolic chamber. The mice were killed after $6 \mathrm{wk}$ of receiving the diet, following a 4-h fast, with an intraperitoneal injection of Somnopentyl (Kyoritsu Seiyaku Corporation, Tokyo, Japan). Blood samples were collected from periorbital puncture. The liver and white adipose tissue (WAT) weight were measured and removed. The triglyceride and total cholesterol levels in the plasma were measured by colorimetric slides, using a FUJI DRI-CHEM 3500 analyzer (FujiFilm Medical Co., Ltd., Tokyo, Japan). The triglyceride, total cholesterol and free fatty acid levels of crude lipid samples were measured by the Wako TG E, TC E, and NEFA C test kits (Wako Pure Chemical Industries, Ltd., Osaka, Japan). Crude lipid extracts were obtained by the method described by Bligh and Dyer. ${ }^{17)}$ Total RNA was extracted from the liver by using the Trizol reagent (Invitrogen, Carlsbad, CA, USA). Real-time reverse transcription polymerase chain reaction (RT-PCR) analysis was performed with an ABI Prism 7000 and 7500 thermal cycler (Applied Biosystems, Tokyo, Japan), using QuantiTect SYBR Green RT-PCR (Qiagen, Hilden, Germany) with gene-specific primers. The mRNA levels of the liver in all groups are represented as the ratios to the mRNA levels in the control group.

Statistical comparisons of the four groups were made by one-way ANOVA, and each group was compared with the others by Tukey HSD test (SPSS 12.0J for Windows, SPSS Japan, Inc., Tokyo, Japan). Statistical comparisons of the two groups were made with the same software by Student's $t$-test. $p$ values less than 0.05 are considered to indicate statistical significance. Values are means \pm SE.
Body weight after 3 wk was significantly increased and that after 6 wk tended to increase $(p=0.050)$ in the BA group compared with that in the control group (Table 2). Body weight after $6 \mathrm{wk}$ was significantly decreased in both the BR and the FR groups compared with that in the BA group. The WAT weight was significantly increased and the liver weight tended to increase $(p=0.060)$ in the BA group compared with that in the control group. The WAT and liver weights in both the BR and FR groups were significantly decreased compared with those in the BA group. The plasma triglyceride and total cholesterol levels were lower in the FR group than those in the other groups, while the plasma free fatty acid levels tended to be lower in the FR group than those in the BA group $(p=0.082)$. The respective total lipids levels and triglyceride levels in the liver were significantly higher and tended to be higher $(p=0.089)$ in the BA group than those in the control group. Although total lipids and triglyceride levels in the liver of both the BR and FR groups were lower than those in the BA group, these differences were only significant in the FR group. Total cholesterol levels in the liver tended to be lower in the BR and FR groups than those in the BA group (BR: $p=0.086$, FR: $p=$ $0.059)$. These results show that both fish oil and beef tallow combined with a restricted diet ameliorated hyperlipidemia and fatty liver induced by the high-fat diet. However, the FR group showed greater improvement to hyperlipidemia and fatty liver than the BR group, despite the comparable rate of body and WAT weight reduction. One $\%$ of $\delta$-tocopherol-added fish oil in this study might have some effect on the lipid content of the liver. However, the result of one study has indicated that vitamin E intake did not decrease the lipid content of the liver. ${ }^{18)}$ We have also reported that the fatty acid composition was more effective for improving fatty liver in comparison with $\delta$-tocopherol, because we indicated that fish oil decreased lipids levels in the liver when compared with hydrogenated fish oil, despite containing the same amount of $\delta$-tocopherol. ${ }^{19)}$

To examine the cause for the greater improvement of hyperlipidemia and fatty liver in the FR group, we measured the levels of fatty acid synthase (FAS), acylCoA oxidase (ACO), 3-hydroxy-3-methylglutaryl coenzyme A (HMG-CoA) reductase, and cholesterol $7 \alpha$ hydroxylase (CYP7A1) mRNA in the liver involved in fatty acid synthesis, $\beta$ oxidation, cholesterol synthesis, and cholesterol conversion into bile acids, ${ }^{20,21)}$ and adiponectin levels in plasma which reflects adipose tissue physiology. ${ }^{22)}$ FAS mRNA levels tended to higher in the BA group than those in the control group (Fig. 1A, $p=0.095$ ). Although the levels in both the $\mathrm{BR}$ and FR groups were lower than those in the BA group (FR vs. BA: $p=0.076$ ), the levels in the FR group were significantly lower than those in the $\mathrm{BR}$ group. ACO, HMG-CoA reductase, and CYP7A1 mRNA levels were not significantly different among the four groups (Fig. 1B-D). Adiponectin levels tended to be lower in the BA group than those in the control group ( $p=0.058)$, and the levels in the FR group, but not in the BR group, were significantly higher than those in the BA group (Fig. 1E). It has been reported that fish oil increased the secretion of adiponectin from adipocytes by peroxisome proliferated receptor $\gamma$ stimula- 
Table 2. Body Weight, WAT and Liver Weight, and Lipids Levels in the Plasma and Liver

\begin{tabular}{|c|c|c|c|c|}
\hline & Control & BA & BR & FR \\
\hline Initial body weight (g) & $20.5 \pm 1.6$ & $21.8 \pm 0.3$ & & \\
\hline Body weight at 3 weeks ( $g$ ) & $30.7 \pm 1.7$ & $37.8 \pm 0.9^{* *}$ & & \\
\hline Body weight at 6 weeks ( $g$ ) & $37.3 \pm 2.3^{\mathrm{ab}}$ & $46.9 \pm 3.2^{\mathrm{b}}$ & $35.3 \pm 2.3^{\mathrm{a}}$ & $34.7 \pm 2.5^{\mathrm{a}}$ \\
\hline WAT weight (g) & $2.81 \pm 0.26^{\mathrm{a}}$ & $6.18 \pm 0.85^{\mathrm{b}}$ & $3.56 \pm 0.47^{\mathrm{a}}$ & $3.12 \pm 0.47^{\mathrm{a}}$ \\
\hline Liver weight (g) & $1.29 \pm 0.09^{\mathrm{ab}}$ & $2.53 \pm 0.58^{\mathrm{a}}$ & $1.15 \pm 0.11^{\mathrm{b}}$ & $1.14 \pm 0.10^{\mathrm{b}}$ \\
\hline \multicolumn{5}{|l|}{ Plasma } \\
\hline Triglyceride (mmol/L) & $1.75 \pm 0.22^{\mathrm{a}}$ & $1.25 \pm 0.18^{\mathrm{ab}}$ & $1.29 \pm 0.16^{\mathrm{ab}}$ & $0.69 \pm 0.08^{b}$ \\
\hline Total cholesterol (mmol/L) & $2.98 \pm 0.42^{\mathrm{ab}}$ & $3.74 \pm 0.52^{\mathrm{a}}$ & $3.06 \pm 0.51^{\mathrm{ab}}$ & $1.66 \pm 0.15^{\mathrm{b}}$ \\
\hline Free fatty acid $(\mathrm{mEq} / \mathrm{L})$ & $0.434 \pm 0.034$ & $0.451 \pm 0.014$ & $0.423 \pm 0.03$ & $0.358 \pm 0.024$ \\
\hline \multicolumn{5}{|l|}{ Liver } \\
\hline Total lipids (mg/g liver) & $70.9 \pm 13.4^{\mathrm{a}}$ & $227.7 \pm 59.2^{\mathrm{b}}$ & $114.7 \pm 15.2^{\mathrm{ab}}$ & $64.4 \pm 16.2^{\mathrm{a}}$ \\
\hline Triglyceride (mg/g liver) & $43.4 \pm 16.5^{\mathrm{ab}}$ & $100.4 \pm 14.7^{\mathrm{b}}$ & $56.7 \pm 24.0^{\mathrm{ab}}$ & $35.8 \pm 13.6^{\mathrm{a}}$ \\
\hline Total cholesterol (mg/g liver) & $7.43 \pm 2.63$ & $15.44 \pm 4.16$ & $6.56 \pm 1.07$ & $5.82 \pm 2.13$ \\
\hline
\end{tabular}

Mice were fed the MF diet (Control) or the B $\operatorname{diet}(\mathrm{BA})$ for $3 \mathrm{wk}$, and then mice fed the B diet were divided into three groups (BA, BR and FR) and each experimental diet was fed for $3 \mathrm{wk}$. After $6 \mathrm{wk}$ of diet consumption, mice were sacrificed after 4-h fasting. Data is shown as mean \pm SE $(\mathrm{n}=4)$. ${ }^{* *}$ Asterisks indicate a significant difference from the control group; $p<0.01$. Means without a common letter differ, $p<0.05$.

A) FAS mRNA in the liver

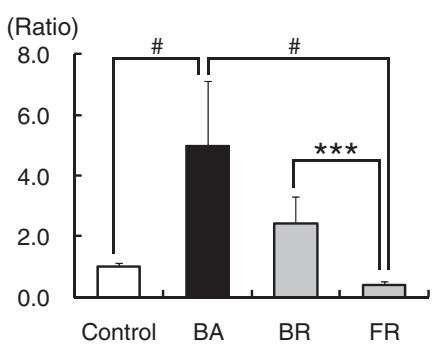

C) HMG-CoA reductase mRNA in the liver

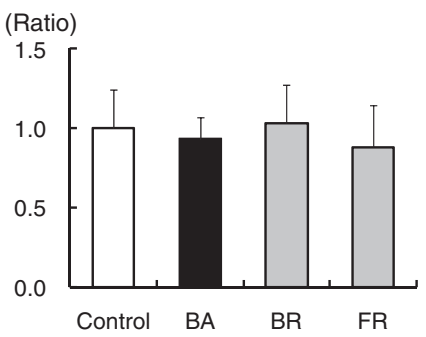

E) Adiponectin in the plasma

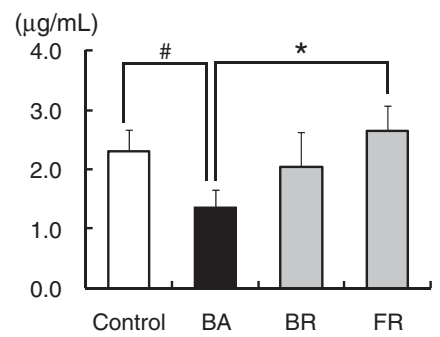

B) ACO mRNA in the liver

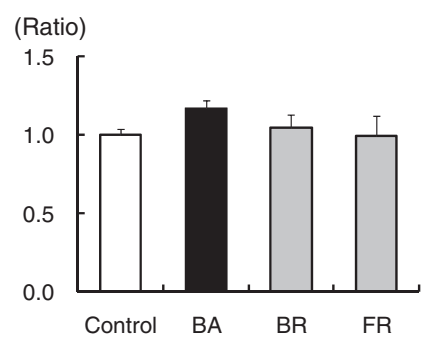

D) CYP7A1 mRNA in the liver

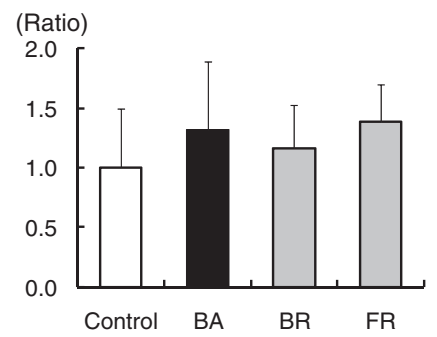

Fig. 1. Relative mRNA Levels in the Liver and Adiponectin Levels in the Plasma.

Mice were sacrificed after 6 wk of receiving the diet and after 4-h of fasting. The liver was removed, and the gene expression levels of (A) fatty acid synthase (FAS), (B) acyl-CoA oxidase (ACO), (C) HMG-CoA reductase, and (D) CYP7A1 were measured by real-time RT-PCR. The gene expression levels are indicated as the relative values to those of the control group. The plasma adiponectin levels were also measured (E). Superscripts indicate the difference: ${ }^{*} p<0.05,{ }^{* *} p<0.01,{ }^{\#} p<0.1$.

tion. ${ }^{23)}$ We confirmed the effect of fish oil under the restriction of food consumption. These results indicate that the FR group showed a much decreased level of fatty acid synthesis in the liver and improved adipose tissue physiology such as smaller adipocyte size than that in the BR group. Further study is needed to elucidate the mechanism for the cholesterol decrease in the FR group.
We evaluated RQ to examine the utilization of lipids as a substrate of energy in the BR and FR groups. It has been reported that low RQ by energy restriction was useful as a marker to predict body weight reduction and an improvement to metabolic disorders. ${ }^{24,25)}$ Although RQ during the night (19:00-7:00) was similar among all the groups (Control: 0.92; BA: 0.86; BR: 0.87; and FR: $0.87)$, that during the day (7:00-19:00) was lower in 
both the BR and FR groups than that in the control and BA groups (Control: 0.92; BA: 0.85; BR: 0.76; FR: 0.77). This result shows that the utilization of lipids was no different between the BR and FR groups, and that energy restriction shifted the substrate for energy from carbohydrates towards lipids during the day in both the BR and FR groups.

In conclusion, food restriction with any type of fat was effective in reducing the body and WAT weights and ameliorating dyslipidemia accompanied by preferential lipid oxidation. However, fish oil feeding combined with food restriction showed a greater improvement to dyslipidemia and fatty liver by the strong suppression of fatty acid synthesis in the liver and the increased adiponectin secretion from the adipose tissue, even though fish oil did not enhance body and WAT weight reduction when compared with beef tallow. The results of this study therefore suggest that fish oil feeding combined with food restriction may be useful for improving the high-fat diet-induced dyslipidemia and adiponectin levels.

\section{Acknowledgments}

We are grateful to NOF Corporation (Tokyo, Japan) for supplying the fish oil.

\section{References}

1) Chan JM, Rimm EB, Colditz GA, Stampfer MJ, and Willett WC, Diabetes Care, 17, 961-969 (1994).

2) Colditz GA, Willett WC, Stampfer MJ, Manson JE, Hennekens CH, Arky RA, and Speizer FE, Am. J. Epidemiol., 132, 501-513 (1990).

3) Manson JE, Colditz GA, Stampfer MJ, Willett WC, Rosner B, Monson RR, Speizer FE, and Hennekens CH, N. Engl. J. Med., 322, 882-889 (1990).

4) Stamler R, Stamler J, Riedlinger WF, Algera G, and Roberts RH, JAMA, 240, 1607-1610 (1978).

5) Blackburn G, Obes. Res., 3, 211s-216s (1995).

6) Goldstein DJ, Int. J. Obes. Relat. Metab. Disord., 16, 397-415 (1992).
7) Carpentier YA, Portois L, and Malaisse WJ, Am. J. Clin. Nutr., 83, 1499S-1504S (2006).

8) Lombardo YB, Hein G, and Chicco A, Lipids, 42, 427-437 (2007).

9) Rossi AS, Lombardo YB, Lacorte JM, Chicco AG, Rouault C, Slama G, and Rizkalla SW, Am. J. Physiol. Regul. Integr. Comp. Physiol., 289, R486-R494 (2005).

10) Gunnarsdottir I, Tomasson H, Kiely M, Martinéz JA, Bandarra NM, Morais MG, and Thorsdottir I, Int. J. Obes., 32, 1105-1112 (2008).

11) Krebs JD, Browning LM, McLean NK, Rothwell JL, Mishra GD, Moore CS, and Jebb SA, Int. J. Obes., 30, 1535-1544 (2006).

12) Mori TA, Bao DQ, Burke V, Puddey IB, Watts GF, and Beilin LJ, Am. J. Clin. Nutr., 70, 817-825 (1999).

13) Ramel A, Jonsdottir MT, and Thorsdottir I, Nutr. Metab. Cardiovasc. Dis., 19, 690-696 (2009).

14) Thorsdottir I, Tomasson H, Gunnarsdottir I, Gisladottir E, Kiely M, Parra MD, Bandarra NM, Schaafsma G, and Martinéz JA, Int. J. Obes., 31, 1560-1566 (2007).

15) Reeves PG, Nielsen FH, and Fahey GCJr, J. Nutr., 123, 19391951 (1993).

16) Ikemoto $\mathrm{S}$, Takahashi $\mathrm{M}$, Tsunoda $\mathrm{N}$, Maruyama $\mathrm{K}$, Itakura $\mathrm{H}$, and Ezaki O, Metabolism, 45, 1539-1546 (1996).

17) Bligh EG and Dyer WJ, Can. J. Biochem. Physiol., 37, 911-917 (1959).

18) Mohamed AI, Hussein AS, Bhathena SJ, and Hafez YS, J. Nutr. Biochem., 13, 435-441 (2002).

19) Shiba S, Tsunoda N, Ito K, Wakutsu M, Muraki E, Sonoda M, Tam PSY, Fujiwara Y, Ikemoto S, and Kasono K, J. Health Sci., 57, 341-349 (2011).

20) Clarke SD and Jump D, Prostaglandins Leukot. Essent. Fatty Acids, 57, 65-69 (1997).

21) Russell DW, Cardiovasc. Drugs Ther., 6, 103-110 (1992).

22) Lu JY, Huang KC, Chang LC, Huang YS, Chi YC, Su TC, Chen CL, and Yang WS, J. Biomed. Sci., 15, 565-576 (2008).

23) Neschen S, Morino K, Rossbacher JC, Pongratz RL, Cline GW, Sono S, Gillum M, and Shulman GI, Diabetes, 55, 924-928 (2006).

24) Assimacopoulos-Jeannet F, Moinat M, Muzzin P, Colomb C, Jeanrenaud B, Girardier L, Giacobino JP, and Seydoux J, Am. J. Physiol., 260, R278-R283 (1991).

25) Valtueña S, Solà R, and Salas-Salvadó J, Int. J. Obes. Relat. Metab. Disord., 21, 267-273 (1997). 